\title{
WICS MODEL'S IMPACT UPON SUCCESSFUL MILITARY LEADERS
}

\author{
Mădălina-Ioana BĂDILĂ \\ “Nicolae Bălcescu” Land Forces Academy Sibiu, Romania \\ Lil_saint_mada@ymail.com
}

\begin{abstract}
What does actually define successful leadership? We all know that one of the fundamental principles of the inter-personal connections represents the similarity reasoning - which means that we are attracted to people like ourselves. Applying this principle to the military organizational background, it can be observed that former leaders who occupy a decision-making position in an organization seek for future appointed leaders with similar ideas and competencies. This can only be achieved through a profound process of individual evaluation, based on the standardization in the military. Nevertheless, it has been frequently demonstrated that standardized tests may not properly dignify the leader's skills. Therefore, we can avoid being deprived of our personal aptnesses by expanding our knowledge in the matter of successful leading skills through accepting and implementing innovative leadership perspectives such as the one WICS model presents. The abbreviated model involves the harmonious transposition of specific components that define successful leaders through the synthesis of the intelligence, creativity and wisdom.
\end{abstract}

\section{Keywords: WICS, meta-components, military leader, success}

\section{Introduction to WICS network}

The skills one needs to survive today are so much broader than the skills that old conceptions included. Today's world is in a quick process of development, thus it is important for the leader to demonstrate the power of his memory and analytical skills, but also adaptability to the environment in order to maintain good relationships and reach the organizational goals.

It has been shown that effectiveness in any situation is neither the result of a unique leading style or a standard pattern nor it features the uniqueness of certain traits.

How can an organization characterized by change boost creative sources that meet the organizational objectives and what does the person in power need to obtain the title of effective leader? Well, a modern perspective is the model WICS that could answer the dilemma related to the efficient leading of modern organizations.
The vision concerning effective leadership in the army is always made essential by the idea that people will perceive as good the leading person who knows what to do and how to do it.

Being among notorious experts in psychology and psychiatry, Robert Sternberg proposed a model of gifted leadership, abbreviated WICS - Wisdom, Intelligence, Creativity Synthesized. The model prospective includes both skills and attitudes related to the activity of the leader. The model can be simply explained by a person's decision to do something, but the traits found in this theory exceed the previously discovered paradigms. [1]

The leader applies these three metacomponents in a personal level, underlining his self-development as well as in the decision-making process that is to be made inside the organization. 
Understanding WICS is based on the premise that no one is good at everything and everyone is capable of something. Smart people identify strengths and weaknesses, based on which they form an effective work pattern.

The basis of this perspective represents successful intelligence which prints the leader's efficiency by generating new ideas, verifying the usefulness of those new ideas through the filter of academic intelligence, persuading subordinates of the solutions using practical intelligence and having the necessary wisdom to align new ideas to the interests of all members of the organization and the organizational objectives. [2]

In this regard, the leader uses creativity to innovate and adapt to unforeseen, being smart enough for analysis and deployment of the proposed ideas, and, of course, wise in order to reflect moral values at the level of intrapersonal, interpersonal and extrapersonal levels.

To illustrate the power of creativity, creative-intellectual skills are essential to identify good problems to solve and then defining and redefining them until they are understood in order to apply solutions.

Another important implication resulting from the outline of this network refers to the interaction of wisdom, intelligence, creativity and knowledge in the pursuit of the common good. It can be observed the immense need to balance the interests of the leader, of the subordinates and of the organization, on the short and long term, shuffling moral values in order to adapt, form and select environments. [3]

A person can be intelligent without being creative or wise. To be creative, a person needs creative intelligence to formulate good problems, analytical intelligence to put the solutions in unison with problems, and practical intelligence to ensure that followers understand their value, yet does not require being wise.

Simultaneously, a wise person is essential to be both intelligent and creative, since they both determine the formulation of solutions through consideration of the interests of all parts, regardless of timing.

Sternberg argues that good leaders exhibit these three skills that can be improved. Therefore, it appears that the sequential fulfillment of these attributes leads to the becoming of good leaders, decent for society, but never exceptional. [4]

\subsection{The significance and institutional potential of WICS model in leadership}

Leader's contribution represents the generation of favourable circumstances and alignment of the organization to the creative upgrade which epitomizes potential problems.

Thus, the defined model has a few implications. One would be that it involves certain favorable outputs resulting from the managing activity. In principle, these are determined by the extent to which leaders convey a message aligned to subordinates needs in a convincing manner, which facilitates implementation, in order to ensure that subordinates comply with its intended purpose.

Contribution to devising fresh ideas is perfected by intellectual skills and dispositions for deciding on the usefulness of the ideas and persuasion of the followers, wisdom-related skills and dispositions to assess the effects of short and long term on the self, other individuals or institutions.

In the military organization, leaders face numerous problems altering from personal domestic problems, as the everyday-type problems, to abstract problems of contextualization, according to the occupied position in the flowchart.

The way the leader behaves as an authority within the organization reflects its attitude towards decisions. The degree to which leaders summarize the three dimensions depends on factors such as the act of creation, the power of knowledge, thinking styles, personality attributes, some motivational attributes etc. Reflection of meta-components, is, we believe, quite obvious in the military leadership to a smaller or greater extent. 


\section{WICS model's impact upon the military leader}

The aim of this research involves building the vision concerning military structures management in the context of synthetizing of intelligence, creativity and wisdom, as well as generating an understanding of leadership challenges and meanings that leaders associate with military situations. Innovation and practical thinking of the military leader refer to the aimed goal, the type of manoeuver, the course of action, combat disposition resources, scene, time of the attack and so on.

The main ideas we focused our efforts on conduct the impact of the WICS network upon the efficient achievement of leadership challenges in times of peace or conflict and the angle of incidence within the tactical, operational and strategic levels. WICS model indicates that effective leadership is a sinuous process because it involves various elements that interfere the position or situation in which the leader acts. To understand the involvement of the network, we will highlight the connection between this type of challenges and model's dimensions, customized on tactical subunits.

In fact, we centered battalion-level leadership, being the most visible intersection of the debutant leaders with the more experienced ones. The researched institution prepares military structures to act in time of peace or conflict, therefore it created the opportunity of investigating military leaders participating in the noncombat Resolute Support Mission undertaken between 2015 - 2016 in the region of Afghanistan.

Apparently, 10 military personnel stood out due to their leading positions in the organizational structure, which combines elements acquired throughout company duties and practical issues driving from headquarter conformations procedures.

The SOARA research method on behavioral interview proved beneficial, because of the possibility to demonstrate the expression of the network's dimensions in behavioral past of the leaders.

Our attempt is to select and provide a basis for developing the professionalism of military leaders who exhibit positive influence in both their own lives and in the organizational world.

\subsection{Research findings}

Interviewed subjects presented similarities in judgements regarding the applicability WICS network both in activities specific to the scene of operations, as well as those undertaken carried out in peacetime.

Intelligence, creativity and wisdom can tilt the balance of a mission due to the multitude of tasks proposed for reaching the end state. This means that the leader is responsible for preparing the structure before deployment, deployment, execution of the mission entrusted, followed by the completion of the mission and redeployment of the subunits.

The leader plays an important part in gaining success of the subunits, in all the stages of the mission, since he must convince the subordinates of organizational goals, the course of action established in the decision-making process and the aftermath. Moreover, participants believe that these dimensions are reflected in the scene of operations to a limited extent, because military leaders must obey the rules and regulations of international humanitarian law and are less funded by their own experience and believes.

At the tactical level, leaders must be prepared to successfully perform tasks, but as we move forward in the chain of command responsibility extends considerably and it becomes clear that leaders are not only leaders but also leaders of their sub-leaders.

The complexity of contingency includes combat training, providing measures of insurance and protection of the force during peacetime, training for carrying the fight, the discovery of new targets referral to the dangers, carrying out sessions of first aid. 
Officers who participated in the study presented indicators of intelligence, creativity and wisdom.

The results suggest that those highly creative often have developed intellectual skills, but this is not always true, and vice versa. Leaders with analytical skills have a harder time training their creative potential as long as they do not show enough creative thinking. The results from the interview's stages are reflected in the figure below. [5]

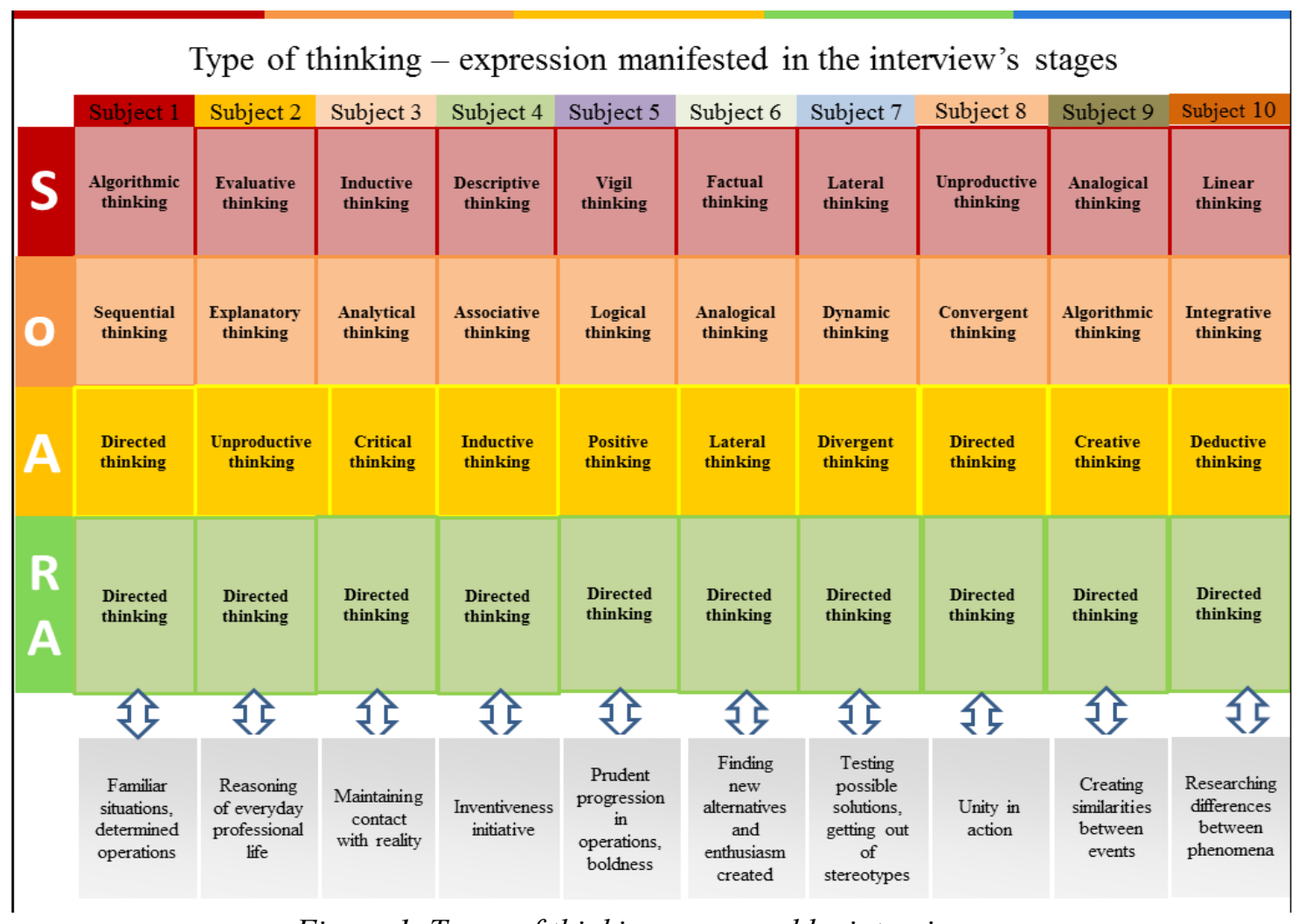

Figure 1. Types of thinking expressed by interviewers

The leader who mixes creativity with wisdom will not have difficulty in formulating viable solutions. On the other hand, creative freedom and the modes of action differ from one leader to another, as a rookie's actions cannot be equated with those of one with experience.

The three dimensions simultaneously apply in all circumstances, making it clear that there are certain factors that require specific features, such as: tactical environment in which the mission is conducted (location, time, forces at disposal, civil population, the type of mission, ammunition, etc.); resources for analysis, planning, execution; potential risks in the operational environment that may affect the fulfillment of the mission; the resources available for accomplishing tasks.
The components must be understood in an interdependent manner, with flexible worth once applied with the functions of leadership.

For tactical and operational leader, the problems encountered are solved by documentation from the military regulations, asking for the opinion of subordinates, advice from other members of the organization or the implementation of simulations training when the solutions are not covered at all in operational procedures. At the strategic level, WICS network has a greater share in the managing and leading activities, due to the decision-making process as it requires solving problems whose conditions may exceed the written or unwritten patterns, which distribute orders to operational and tactical leaders. 
As the hypotheses, we quantified a number of variables, namely the following: intelligence was highlighted by pragmatism, relevance, structure and logic; creativity emerged from originality, innovation quality, communication, and closure to the task; wisdom was observed from the cold judgment, opportunity and the excitement created by the participants.

The results were scored on a four structural scale corresponding to the following amenability: 8 points to a very large extent, 6 points to a great extent, 4 points in a moderate extent and 2 points in small extent for the favourable enounciations. This kind of rating specified in Tabel 1 allowed the reflection of the meta-components in challenges of modern leadership, along with the applicability of the components at the tactical level and the degree of their transposing in a specific combat situation.

Tabel 1. Research findings raking

\begin{tabular}{|c|c|c|c|}
\hline No. crt. & $\begin{array}{c}\text { WICS network's } \\
\text { impact upon leadership }\end{array}$ & $\begin{array}{c}\text { Applicability of meta- } \\
\text { components in tactical } \\
\text { leadership }\end{array}$ & $\begin{array}{c}\text { Putting the model into } \\
\text { practice in a conflict }\end{array}$ \\
\hline Subject 1 & 6 & 4 & 2 \\
\hline Subject 2 & 6 & 2 & 2 \\
\hline Subject 3 & 2 & 2 & 4 \\
\hline Subject 4 & 2 & 2 & 2 \\
\hline Subject 5 & 8 & 2 & 2 \\
\hline Subject 6 & 4 & 4 & 2 \\
\hline Subject 7 & 8 & 4 & 2 \\
\hline Subject 8 & 6 & 4 & 2 \\
\hline Subject 9 & 8 & 2 & 24 \\
\hline Subject 10 & 6 & 4 & \\
\hline TOTAL & 56 & 30 & 2 \\
\hline
\end{tabular}

In this research, all the military leaders have concluded that the intelligence, creativity and wisdom represents important skills that a leader must demonstrate, and synthesizing them into working tasks plays a decisive role in the process of formation, as it can be seen in Figure 2.

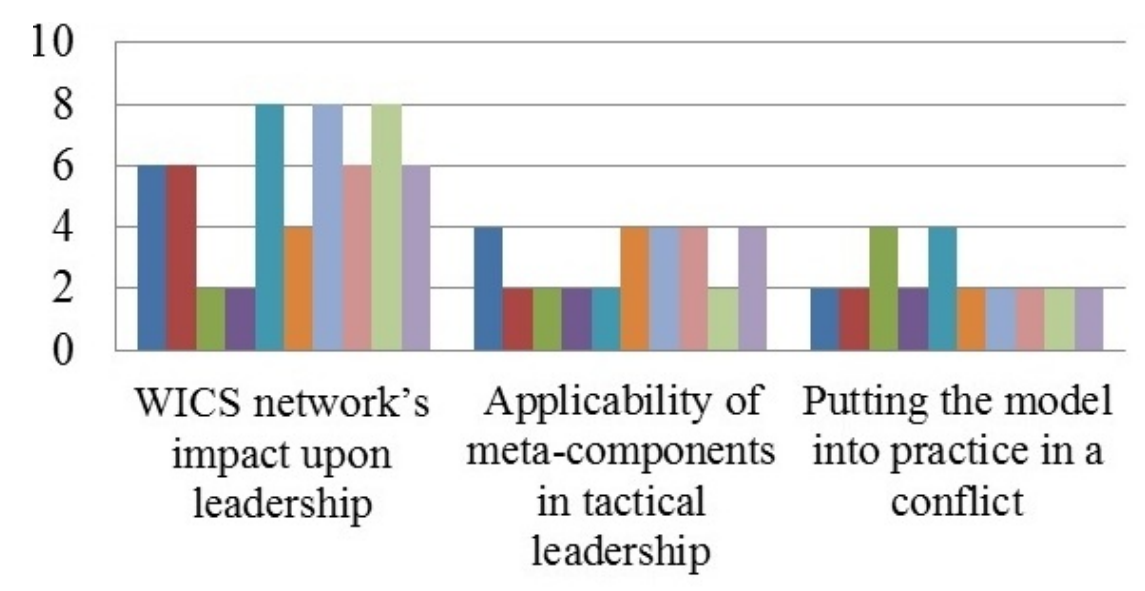

- Subject 1

- Subject 2

- Subject 3

- Subject 4

- Subject 5

- Subject 6

Subject 7

Subject 8

Subject 9

- Subject 10

Figure 2. WICS model's impact upon successful military leaders

It is clear from the results that as we advance in the military hierarchy the elements of intelligence, creativity and wisdom unify to a moderate extent.
WICS components create a relevant image in the military leadership, but they are more visible within the strategic level of the armed forces, as they must be first located 
in the top of the hierarchy, so that later they can be passed on to the whole organization through customized orders.

The higher the level, the more extent the personal contracts are and the leader's influence is of life and death as the layout of the order ensures the success of the defence policies, so the effectiveness of the entire military institution.

\section{Conclusions}

The network described in the previous sections has a universal nature, being available in every domain.

Overcoming the difficulties that may arise in adapting to the WICS model can be achieved by accepting elements of dynamism and glorifying leaders by continuous education and training, thus participating intensely in the preparation of strategies able to promote the configuration of future military organization.
In addition to these efforts, it is necessary to invest in training programs in order get acquainted to the model, as well as assuming projects that stimulate intelligence, creativity and wisdom in the military.

The viability of the model into the world leadership is verified, as leaders must be creative in inventing ideas, analytical intelligent to approach the purpose of those ideas, practical intelligent for storytelling and making subordinates sure of the necessity of the ideas and wise for ensuring the common good.

All in all, the WICS fosters both professionalism and other aspects of life, for it gives guidance in career no matter the position in the hierarchy. It can be only beneficial a model that simplifies the art of leading, whereas it shows an easier way of understanding the concept of a good leader.

\section{References}

[1] Robert Sternberg, WICS: A model of positive educational leadership comprising Wisdom, Intelligence, Creativity Synthesized, Educational Psychology, Vol. 17, No. 3, p. 203, 2005.

[2] Robert. Sternberg, WICS: A Model of educational leadership, The Educational Forum, Vol. 68, No. 2, p. 113, 2004.

[3] Robert Sternberg, A Balance theory of wisdom, Review of General Psychology, No. 2, pp. 347-365, 1998.

[4] Robert Sternberg, The WICS model of leadership, The Oxford handbook of leadership, New York, Oxford University Press, 2012.

[5] Tabel adapted after the Interview Guide proiected by Denise Jodelet in 1974.

[6] John Adair, How to Grow Leaders: The Seven Key Principles of Effective Leadership, București, Meteor Press, 2014.

[7] Bennis Warren, Burt. Nanus, Leaders: Strategies for taking charge, trad: L. Decei, Bucharest, Business Tech International Press, 2000.

[8] Lucian Culda, Leaders in organizations, Bucharest, Centrul de Studii Sociale ProcesualOrganice, 2005.

[9] Dean Williams, Real Leadership: Helping People and Organizations Face Their Toughest Challenges, Bucharest, CODECS Press, 2007. 